\title{
Survival Strategies for Businesses during Covid-19 Lockdown
}

\section{OPEN ACCESS}

Manuscript ID:

MGT-2021-08033533

Volume: 8

Issue: 3

Month: January

Year: 2021

P-ISSN: 2321-4643

E-ISSN: 2581-9402

Received: 15.10 .2020

Accepted: 25.11.2020

Published: 01.01.2021

Citation:

Nivetha, P and Sudhamathi,

S. "Survival Strategies for

Businesses during Covid-19

Lockdown." Shanlax

International Journal of

Management, vol. 8, no. 3, 2021, pp. 79-82.

DOI:

https://doi.org/10.34293/

management.v8i3.3533

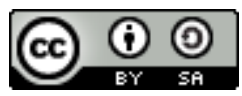

This work is licensed under a Creative Commons Attribution-ShareAlike 4.0 International License.

\author{
P. Nivetha \\ Ph. D. Scholar, Alagappa Institute of Management, Karaikudi, Tamil Nadu, India
}

\author{
S. Sudhamathi \\ Assistant Professor, Alagappa Institute of Management, Karaikudi, Tamil Nadu, India
}

\begin{abstract}
The COVID-19 pestilence is a sharp admonition that pandemics have existed before and will keep on happening later on, as other only here and there happening fiascoes. Regardless of whether we are frail to evade the appearance of hurtful infections, we should plan to hose their consequences for human progress. All through the world, the most recent pestilence has had genuine financial impacts, and it doesn't seem like each country would be unaffected. In addition to the fact that this has financial ramifications; quite a bit of society is affected, which has added to extraordinary movements in how organizations act and how buyers act. Many anticipated issues with getting to the administration, notwithstanding, for example, regulatory difficulties and qualification challenges. We additionally test take-up rates and market dependability results for advances contrasted with awards based activities utilizing exploratory change.
\end{abstract}

Keywords: COVID-19, Businesses act, Bureaucratic hassles, Business resilience effects

\section{Introduction}

Internationally, we are at the center of a Covid-19 pandemic that conveys two sorts of paralyzes on countries: a prosperity stagger and a money related daze. The ways to deal with dealing with the transmission fuse structure methodology, carried on to the idea of the infection that is extremely contagious, for example, burden of social rejection, self-confinement at home, hierarchical end and open workplaces, impediments on the development of a whole nation and even lockout. These tests may possibly have horrible ramifications for monetary frameworks around the world. In different dialects, to hold the regular action down, fruitful scourge control includes the economy of a nation. This has caused fears about a mystery and supported monetary slump. Kristalina Georgieva, top of the International Monetary Fund, said on April 9 that 2020 could see the most horrendous worldwide monetary outcome since the Great Depression of the 1930s, with more than 170 countries presented to unfavorable per capita GDP development because of the fuming Covid pandemic. In the past, illnesses, for example, smallpox, plague and polio should have been directed by India. For these people, there were somewhat genuine scenes. Anyway, Covid-19, which began in China in December of 2019. To slow the spread of the novel Covid, policymakers worldwide have embraced tight control systems. This involves imprisonment and lockdowns, travel limitations and boycotts, the prohibiting of enormous social occasions, and incomplete closures of schools and financial exercises. These estimates taken to ensure general wellbeing have an immediate and backhanded effect on monetary possibilities in a period of emergency. This section examinations the effect of the pandemic on worldwide exchange streams. The insights show that fares and imports in the nations where lockout measures have been 
presented and their exchange accomplices have been affected by production network interruptions and interior interest. Information examination shows that the hardest impact has been on certain business sectors and locales.

\section{Survival Strategies for Businesses during COVID-19 Lockdown}

It is a direct result of the downturn of Covid-19, trailed by social separating and a public lockdown, organizations face significant effects paying little mind to how settled they are and need to re-take a gander at how their organization is overseen and executed, similar to returning to their corporate arrangement. It has been outlandish for most organizations to keep their monetary wheels turning all through the lockout time because of the diminished income turnover and the general vulnerability in the worldwide monetary atmosphere. Start-up firms should stick to another assortment of rules and be aware of the accompanying elements to lessen chances and to endure the stagnation brought about by the results of COVID-19.

\section{Tracking Expenses against the Revenue Status}

For organizations to do a thorough investigation of their fixed and unforeseen costs just as their real deals through this infection is of most extreme significance. This estimation will incorporate an away from of where an association is monetarily situated and help business people plan for the future in the current perturbed atmosphere. Furthermore, this procedure can be stretched out after the pandemic impact settles.

\section{Checking the Feasibility of the Business Model}

Given that the world is changing each week and more regrettable), it is important to reexamine the promoting technique and reconsider where the organization is in accordance with the projections of income and consumptions. This is additionally an indispensable time for checking current monetary measurements and income. Be aware of what the runway resembles. Organizations need to dissect the effect on new deals, assortments, credit periods and possible awful obligations.

\section{Plan Policies for Next 3 Months / 9 Months / 18 Months}

Since estimating how long this pandemic will last is far-fetched, it is significant that all alternatives are readied. On the off chance that we think of it as a three-month issue, unexpected costs, for example, preparing, advancement, transport, and so on will rapidly be dispensed with. Nonetheless, if the emergency goes on for a very long time to a year, business visionaries should reconfigure their business system to relieve unexpected costs, reconsider fixed spending (lease, compensations, renting installments for hardware, and so on, and center exclusively around indispensable endurance necessities. It very well may be a decent move to reevaluate the business approach, selling on the web versus face to face. On the off chance that you need to cut or increase.

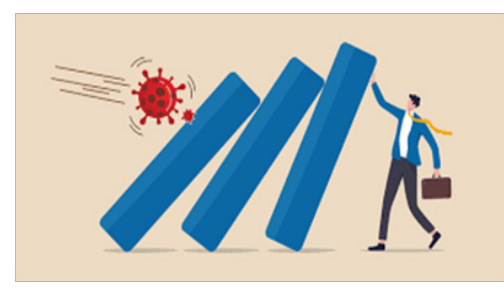

\section{Be Patient in Securing Investments}

Each organization needs assets to run and the difficulty that crosses the brain of each originator/ business person in these troublesome occasions is the place where they can get the subsidizing from. There are a few finances that have enough money to send for the following not many years and they don't avoid it.

\section{Communicate Transparently with your Customers}

We are all in this together, yet the best methodology is to speak the truth about the thing the organization is experiencing for your customers. However long the discussion is direct, customers will identify with associations confronting an emergency. To think about their perspective on the item/arrangement gave by you, associate with customers.

\section{Maintaining Healthy Relationship with Contracted Parties}

It is sensible that during the lockdown, it tends to be difficult to take care of merchants/providers. Notwithstanding, if there will be some deferral in 
installments with the goal that they would all be able to be readied and there is no harshness in this all around extreme second, it will be acceptable to give the retailers, producers, property managers and so forth abundant admonition.

\section{Managing Employees \& Related Optimization}

For significant organizations arranging cutbacks, diminishing the compensation of the most lucrative executive/workers might be the essential choice to attempt to keep the people who would least be able to bear to chance their utilized positions. Nonetheless, when the opportunity arrives to settle on the extreme choice, look out for government mandates with empathy, and give extra remuneration if and when fitting. Such execution can happen just a single time and not in advances with the end goal that it would not influence the profitability of laborers.

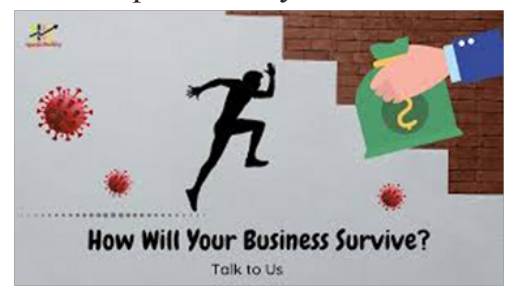

\section{Keep Your Team Engaged}

Your group relies upon you, so stay up with the latest on every turn of events. As an advertiser, through video conferencing stages like Zoom and Google Hangouts, it is your obligation to keep your colleagues included and stay connected with them. Keeping up cheerful moods inside group \& knowing the overall air inside the telecommuters is truly basic.

\section{Positive Impact}

We start off with energy. "Atmanirbhar Bharat", "New Educational Policy 2020", "Work Codes", "One Nation One Ration Card", new MSME strategies, thus a lot more is presented by Covid-19. Both of the above have enormously re-constructed the trust of Indian firms, representatives, and society on the loose. Without a doubt, a push has been given to the Indian assembling area with Atmanirbhar Bharat, and new MSME approaches.

As per the 2018 International Labor Organization, India has the second most elevated workforce around the world. In 2019, Post-Covid positioned India 63rd in the World Bank's Ease of Doing
Business classification, which was a noticeable hop from position 142 five years sooner. While we can anticipate that the wellbeing and care industry, the drug business, the indispensable item area, the training business are currently predominantly dependent on numerous variables, for example, the restriction on Chinese merchandise, Japan burning through 2.2 billion in bringing Japanese organizations out of China, rising import obligation, levies and burdens, and, most outstandingly, India positions 'third' in the Manufacturing Risk Index

\section{Negative Impact}

Coronavirus affected the Indian economy, to such an extent that in this article it can not be distributed succinctly. Nonetheless, the most observable macroeconomic and microeconomic markers that are influenced are GDP, which diminished by $23.9 \%$ in the second quarter of 2020. India, despite the fact that it is improving and as yet battling. Accordingly, the difficult remaining parts: Covid-19's positive or negative effect? Because of Covid-19, India is the third most influenced district. Money, producing, land, utilities, mining and quarrying, lodgings and transportation, and others are the areas that have unmistakably been influenced. Fares and imports all dropped. Lamentably, all notices with either "briefly shut" or "to-let" loads up composed on them are put by miniature and little organizations, standard bets, and that's just the beginning. The deficiency of autonomous stores, wholesalers, sellers, makers, and society everywhere is shocking and transitory.

\section{Conclusion}

The spiraling and unavoidable COVID-19 pandemic has distorted the planet's prospering business sectors in tricky and uncertain terms. In any case, it appeared, truth be told, that the new plunge appeared to be principally unmistakable from the past downturns that shocked the world's monetary request. While countries, combinations, organizations and multinationals need to think about the extent of the pandemic, there is unquestionably a requirement for time to plan for a future that is steady \& basically more manageable for living \& working.

Despite the fact that the unanticipated situation has made incredible harm the economy, particularly 
during times of lockout, the country should discover its way through it by presenting financial measures. On the off chance that the public government imagines, security of all life and prosperity is required. Financial development should proceed with continuously after the screening of the workforce. Exacting avoidance move should be made by the area to ensure the wellbeing of laborers. While government approaches and changes to save the economy should be appropriately actualized, industry, common society and society have an equivalent influence in holding balance. Until the sickness will be destroyed, the ideas of common isolation, evasion or abrogation of exercises and the utilization of veils and purifying specialists should be the lifestyle. The economy is compared with the social activities of mankind during this period, yet it isn't the public authority alone that is answerable for making a back monetary move.

The probability of a worldwide downturn because of COVID-19 out of 2020 and 2021 would be extraordinarily solid, as it has been perceived globally that it is unavoidable to close down all financial exercises to follow the spread of COVID-19 yield, request and exchange. On account of COVID-19, as a result of an inventory stun, an interest stun and a value stun, the idea of the closure is one of a kind. The financial recuperation relies upon the circumstance and greatness of government uphold, the volume of corporate obligation and how organizations and economies are managing diminished interest. A basic instrument for saving numerous lives is government help to individuals most out of luck (predominantly sloppy undertakings, travelers and weak networks).

Nonetheless, emergency presents uncommon opportunity to reexamine way taken for an individual, culture \& human advancement to advance. For Indian economy, COVID-19 pandemic has an unmistakable message follow comprehensive improvement procedures zeroed in on independence, libertarian frameworks \& naturally benevolent models.

\section{References}

Barro, Robert J., et al. "The Coronavirus and the Great Influenza Pandemic: Lessons from the "Spanish Flu" for the Coronavirus's Potential Effects on Mortality and Economic Activity." NBER Working Paper No. 26866, 2020.

Bettinger, Eric P., et al. "The Role of Application Assistance and Information in College Decisions: Results from the H\&R Block FAFSA Experiment." Quarterly Journal of Economics, vol. 127, 2012, pp. 1205-1242.

DellaVigna, Stefano, and Matthew Gentzkow. "Uniform Pricing in U.S. Retail Chains." The Quarterly Journal of Economics, vol. 134, no. 4, 2019, pp. 2011-2084.

Faulkender, Michael. Cash Holdings among Small Businesses, 2002.

Finkelstein, Amy, and Matthew J. Notowidigdo. "Take-up and Targeting: Experimental Evidence from SNAP." Quarterly Journal of Economics, vol. 134, 2019, pp. 1505-1556.

Garrett, Thomas A. Economic Effects of the 1918 Influenza Pandemic: Implications for a Modern-Day Pandemic, Federal Reserve Bank of St. Louis, 2007.

Garrett, Thomas A. "Pandemic Economics: The 1918 Influenza and its Modern-Day Implications." Federal Reserve Bank of St. Louis Review, 2008, pp. 75-94.

Goldfarb, Avi, and Mo Xiao. "Who Thinks about the Competition? Managerial Ability and Strategic Entry in US Local Telephone Markets." American Economic Review, vol. 101, no. 7, 2011, pp. 3130-3161.

Rocca, Maurizio, La, et al. "Cash Holdings and SME Performance in Europe: The Role of FirmSpecific and Macroeconomic Moderators." Small Business Economics, 2019.

Shlain, Avner S. More than a Penny's Worth: LeftDigit Bias and Firm Pricing, 2018.

\section{Author details}

P. Nivetha, Ph. D. Scholar, Alagappa Institute of Management, Karaikudi, Tamil Nadu, India

Dr. S. Sudhamathi, Assistant Professor, Alagappa Institute of Management, Karaikudi, Tamil Nadu, India

Email ID: sudhamathiprem@gmail.com 